\title{
ANTSIWINIK. EXPRESARSE COMO HOMOSEXUAL EN UNA SECUNDARIA DE CONTEXTO INDÍGENA
}

\section{Antsiwinik. EXPressing One's HomoseXuality in An Indigenous High SchoOL}

\author{
Amadeo Hernández-Silvano* \\ Rogelio Ernesto Marcial-Zavala** \\ Manuel Alejandro Moreno-Muñoz*** \\ DOI: http://dx.doi.org/10.29043/liminar.vl8il.724
}

Resumen: El presente artículo está basado en una investigación de enfoque etnográfico realizada entre 2016 y 2018 , y ofrece un acercamiento a la percepción de lo que se podrían denominar identidades homosexuales en contextos indígenas, específicamente en una escuela secundaria ubicada en un ejido del municipio de Ocosingo, Chiapas. Se analizan situaciones conflictivas que experimentaron tres alumnos que se habían asumido como antsiwiniketik apartir de la relación con sus compañeros y adultos dentro y fuera de la escuela. Para su análisis se recuperan aportaciones teóricas y conceptos tales como: lucha de poder, heteronorma, sistema sexo-género, estudios de género, teoría queer e interculturalidad.

Palabras clave: conducta sexual; identidad de género; población indígena; educación intercultural; conflicto cultural.

\begin{abstract}
This article outlines ethnographic research conducted between 2016 and 2018, and offers an approach to what could be called homosexual identities in indigenous contexts, specifically in a secondary school located in an ejido of Ocosingo, Chiapas. It analyzes conflictive situations in the lives of three students who have come out as antsiwiniketik [women-men] in terms of their relationships with their classmates and with adults inside and outside the school. For the analysis, I review theoretical contributions and concepts such as power struggles, heteronormativity, sex gender system, gender studies, queer theory, and interculturality.
\end{abstract}

Keywords: sexual behavior; gender identity; indigenous population; intercultural education; cultural conflict.

\footnotetext{
* Amadeo Hernández Silvano. Maestro en Estudios Culturales por la Universidad Autónoma de Chiapas (UNACH), México. Doctorante en Estudios Regionales en la UNACH, México. Temas de especialización: interculturalidad, educación en contextos indígenas y racismo cultural. Correo electrónico: amadeo_356@yahoo.com.mx. ORCID: https:/orcid. org/0000-0001-5892-7990

** Rogelio Ernesto Marcial Zavala. Maestro en Estudios Culturales por la Universidad Autónoma de Chiapas (UNACH), México. Doctorante en Estudios Regionales en la UNACH, México. Temas de especialización: estudios de género, sexualidades, gerontología y vejez diversa. Correo electrónico: ernestomarcial@live.com. ORCID: https:/orcid.org/00000002-1106-1410
}

\begin{abstract}
*** Manuel Alejandro Moreno Muñoz. Maestro en Estudios Culturales por la Universidad Autónoma de Chiapas (UNACH), México. Doctorante en Estudios Regionales en la UNACH, México. Temas de especialización: estudios de género, masculinidades y educación emocional. Correo electrónico: manuel_moreno@msn.com. ORCID: https://orcid.org/0000-0002-4538-1949
\end{abstract}

Enviado a dictamen: 28 de marzo de 2019. Aprobación: 18 de mayo de 2019.

Revisiones: 1 . 


\section{Introducción}

L a visión que se ha forjado en determinados contextos culturales sobre el deber ser en relación con el cuerpo de una persona influye en la sociedad al promover discursos que establecen principios normativos que marcan lo "normal" o "anormal" dentro de cada grupo social. En la escuela influyen estos discursos, por tal razón la educación intercultural es aún una tarea pendiente. Los programas de estudio 2011 de la Secretaría de Educación Pública (SEP) de México retoman la interculturalidad como la posibilidad de establecer "relaciones simétricas" considerando a los denominados pueblos indígenas, pues:

Los Marcos Curriculares tienen como principios generales la contextualización y diversificación. Contextualizan porque permiten acceder a la indagación, profundización e inclusión de los conocimientos de los pueblos y las comunidades desde la perspectiva derivada de su cosmovisión [...] se plantearán desde un enfoque valorativo de lo propio que ayude a desarrollar una identidad positiva en la niñez indígena, que le permita acceder a la interculturalidad con bases culturales bien cimentadas y establecer relaciones simétricas con grupos o individuos de otras culturas, enriquecerse con los conocimientos de otros, dialogar y aportar sus saberes (SEP, 2011:58).

Sin embargo, lo anterior muestra que la educación que se brinda en las escuelas está lejos de retomar, al menos desde los programas de estudio, la diversidad sexo-genérica como parte de la interculturalidad. Indica que la homosexualidad en contextos "indígenas" es un tema invisible desde las instancias educativas y la academia y no se refleja en los programas de estudio, aunque el proceder diario en los entornos educativos está plagado de actos violentos, de opresión social y de discriminación, todo ello sustentado en perspectivas morales, religiosas y biológicas.

En la investigación que se llevó a cabo en la Escuela Secundaria Técnica 62 (EST 62) durante los ciclos escolares 2016-2017 y 2017-2018 se analizó la significación y la vivencia de jóvenes adolescentes indígenas con orientaciones y prácticas sexuales diversas. Esta institución educativa se encuentra ubicada en el ejido Damasco, que se localiza en el municipio de Ocosingo, Chiapas, y pertenece al Sistema Educativo Federal. Desde sus inicios en 1984 y por su ubicación geográfica, brinda educación a alumnos "indígenas"l pertenecientes al grupo cultural denominado "tseltal" (archivos de la escuela).

Hablar de sexualidad en Damasco es poco frecuente, y de diversidad sexo-genérica aún menos; esto es algo que casi no ocurre, como lo expresan los habitantes de la comunidad, quienes aseguran que empezó a tratarse este tema cuando llegaron personas externas y, según afirman, "metieron ideas a los jóvenes". La versión dualista que establece el sistema sexogénero, ${ }^{3}$ es decir, el binario de género - hombre y mujer heterosexuales-, se encuentra instituida en este contexto, y es lo que se considera que debe ser de acuerdo con visiones culturales y religiosas. ${ }^{4}$ En este sentido, según Aguilar:

\section{El sistema sexo-género hace referencia a las formas de relación establecidas entre mujeres y hombres en el seno de una sociedad. Analiza las relaciones producidas bajo un sistema de poder que define condiciones sociales distintas para mujeres y hombres en razón de los papeles y funciones que les han sido asignadas socialmente y de su posición social como seres subordinados o seres con poder sobre los principales recursos (Aguilar, 2008:2).}

Por tanto, el sistema sexo-género establece una conexión entre el sexo biológico, asociado con los genitales, y el género -masculino/femenino-. Estas diferencias biológicas asociadas al sexo marcan comportamientos que socioculturalmente se asignan a los sujetos, pero también representan la reproducción no solo de los roles de género, sino de jerarquías de poder en las sociedades. Rubin también confirma este punto al aseverar que este sistema consiste en: "una serie de acuerdos por los que una sociedad transforma la sexualidad biológica 
en productos de la actividad humana" (1989, citada en Stang, 2018). En el mismo sentido, Wences-Acevedo menciona que:

El sistema sexo-género presupone la heterosexualidad de los sujetos y coloca comportamientos y modos de vivir con relación a la dicotomía hombre-mujer o macho-hembra, sin embargo, con la homosexualidad, estos roles de género impuestos rebasan la norma binaria, pues al tener una relación sexo-afectiva con una persona del mismo sexo, así como las performatividades dentro de la comunidad Lésbico, Gay, Bisexual, Transexual, Transgénero, Travesti e Intersexual (LGBTTTI) se quebrantan las reglas impuestas y normalizadas en el patriarcado (Wences-Acevedo, 2018:195).

De acuerdo con lo anterior, la heterosexualidad, además de ser una forma de relación, opera como un régimen político (Wittig, 2006) que abarca todos los espacios de la vida pública y de la privada. Salazar (2017) hace referencia a que existen espacios designados para ser ocupados por la presencia masculina o por la femenina, así como también distingue el hecho de que hay espacios designados para hombres heterosexuales y no heterosexuales. En este marco, la escuela opera bajo estas regulaciones fundamentadas en la heteronormatividad, y aquello que se aleje del estereotipo de heterosexualidad es cuestionado, señalado y relegado al campo de lo abyecto.

Tal panorama hace que el ser varón en este contexto sea un proceso complejo en el que se combinan el poder, el dolor, el gozo y la violencia, ya que vivimos en una sociedad donde, como propone Ponce:

se menosprecian los atributos "femeninos" y se enaltecen los "masculinos"; es necesario que los "hombres", para ser reconocidos y valorizados, demuestren de manera permanente, incluso obsesiva, que, en contraposición con las mujeres, son racionales, agresivos, valientes, activos, fuertes, atrevidos, aguantadores, independientes; pero, sobre todo, tienen que demostrar control sobre sus emociones y afectos, lo que supuestamente les permite protegerse y ejercer dominio sobre las “mujeres” (Ponce, 2004:8)

En el mismo sentido, Segato señala que: "hay hombres que para gozar del prestigio masculino frente a sus pares son obligados a hacer lo que no tienen ganas y a veces a no hacer lo que tienen ganas: la primera víctima del mandato de masculinidad es el hombre" (2017, citada en Vilche, 2017:s/p). Es evidente entonces que en la comunidad de Damasco este tipo de estereotipos de género son los que rigen el paisaje cotidiano de las actividades sociales, dejando fuera todo lo que tenga relación con diversidad sexo-genérica o lo que se aleje de los mandatos heterosexuales.

\section{El origen del problema}

\begin{abstract}
Así es, siempre me molestan, no hay momentos que mi papá no me regañe, me pega que porque no hablo como hombre, que camino como mujer, se avergüenza de mí [...] es igual aquí [en la escuela], me molestan, no encuentro apoyo con los maestros, se ríen, no hacen nada. Peor mis compañeros, a cada rato me andan toqueteando, ial menos fuera uno solo! No que son todos, y así no me gusta (Ismael, entrevista realizada el 14 de noviembre de 2017).
\end{abstract}

En el comentario anterior Ismael $^{5}$ refleja el rechazo que recibe por parte de su familia, específicamente de su padre, por no llevar a cabo los roles socialmente asignados a los hombres en su contexto, lo que se traduce en agresión física y psicológica. En cuanto a lo que experimenta en la escuela, no está muy lejos de su experiencia familiar, porque la visión heteronormada y la falta de una educación intercultural que incluya la diversidad sexo-genérica da paso a burlas, señalamientos y, como consecuencia, a exclusión e incluso a agresiones físicas sin que los maestros intervengan de manera oportuna. Es así como el concepto de heteronormatividad ${ }^{6}$ cobra sentido en una sociedad heterosexista que naturaliza un ideal binario. Consideramos heteronormatividad como el:

conjunto de las relaciones de poder por medio del 
cual la sexualidad se normaliza y se reglamenta en nuestra cultura y las relaciones heterosexuales idealizadas se institucionalizan y se equiparan con lo que significa ser humano (Warner, 1993: 8). Esto no es otra cosa que la primacía de la imposición de la heterosexualidad como única expresión de la sexualidad válida, posible y exitosa en la sociedad, esto con diversas representaciones casi invisibles de normalización (Wences-Acevedo, 2016:196).

En esta dirección, la formación desde la heteronormatividad es encarnada como orden sexual. De esta manera es como el sociólogo francés Pierre Bourdieu explica la formación bajo la heteronorma, al indicar que se fundamenta en un sistema de oposiciones homólogas entre lo "masculino" — alto, arriba, delante, derecha, recto, seco, duro, sazonado, claro, fuera, público, razón, actividad - y lo "femenino" — abajo, detrás, izquierda, curvo, húmedo, blando, soso, oscuro, dentro, privado, sensibilidad, pasividad-, rangos que se refieren a metáforas de la corporeidad humana. La diferencia biológica entre los sexos y la variedad anatómica entre los órganos sexuales se ha considerado como la justificación natural de la diferencia socialmente establecida entre los sexos y de la división sexual del trabajo (Bourdieu, 2000). En este sentido, la heteronorma sigue en constante reproducción en las sociedades del mundo, en contextos rurales y urbanos, locales y globales; permanece como una idea universal del "deber ser", pero además significa opresión, exclusión y multiplicidad de formas de violencia hacia aquellos sujetos que son diferentes o que simplemente no encajan en los roles asignados desde la sociedad y la cultura.

De acuerdo con Hernández (2012), existe una relación asimétrica entre alumnos "indígenas" y docentes "mestizos" a causa del racismo y de la discriminación étnica. En este caso, si ya existen tensiones culturales y discriminación hacia los grupos "indígenas", la homosexualidad y la pobreza hacen que el problema se acentúe aún más, por lo que los jóvenes de estos grupos se encuentran más vulnerables y excluidos. En este sentido, la escuela, lejos de ser un espacio de integración, inclusión e interculturalidad, suele convertirse en otro espacio en el que se reproduce la discriminación, pues en ella se pueden escuchar expresiones dirigidas a los jóvenes homosexuales como las siguientes: antsiwinik ${ }^{7}$ (hombre-mujer), tsakbon (agárramela, haciendo referencia a los genitales), puto, marica, mampo, cachi, etcétera. $^{8}$ En el trabajo de campo, por poner un ejemplo, se observó cómo algunos compañeros se acercaban a los jóvenes para tocar sus genitales, lo anterior ante la vista de los docentes que no intervinieron. En este sentido, según Wittig:

La sociedad heterosexual está fundada sobre la necesidad del otro/diferente en todos los niveles. No puede funcionar sin este concepto ni económica, ni simbólica, ni lingüística, ni políticamente. Esta necesidad del otro/diferente es una necesidad ontológica para todo el conglomerado de ciencias y de disciplinas que yo llamo el pensamiento heterosexual. Ahora bien, zqué es el otro/diferente sino el dominado? Porque la sociedad heterosexual no es la sociedad que oprime solamente a las lesbianas y a los gays, oprime a muchos otros/ diferentes, oprime a todas las mujeres y a numerosas categorías de hombres, a todos los que están en la situación de dominados. Porque constituir una diferencia y controlarla es "un acto de poder" ya que es un acto esencialmente normativo. Cada cual intenta presentar al otro como diferente. Pero no todo el mundo lo consigue. Hay que ser socialmente dominante para lograrlo (Wittig, 2006, citada en Wences-Acevedo, 2016)

Por las vivencias que se experimentan en su interior, la escuela, lejos de conformarse como un espacio intercultural, es un lugar de conflicto donde la peor parte se la llevan los jóvenes con orientaciones sexuales e identidades distintas a las normadas socialmente. Aunado a esto, el rechazo familiar y comunitario hace que ser sexo-genéricamente diverso en una escuela de contexto indígena cause baja autoestima, temor, coraje, miedo y bajo rendimiento escolar. En esta 
sintonía, durante el trabajo de campo nos encontramos con alumnos rechazados por sus compañeros, padres y maestros, y poco considerados por un sistema educativo que toma en cuenta supuestamente la diversidad.

\section{Proceso metodológico}

El trabajo se dividió en las siguientes cinco partes: revisión de fuentes teóricas, entrevistas a docentes y alumnos, categorización, análisis de resultados y redacción. Para realizar la investigación se habló con personas que participaban en la directiva de la escuela, quienes informaron que en ella estaba registrado un total de 278 alumnos distribuidos en tres grupos y que la plantilla escolar estaba integrada por veintidós personas entre docentes y administrativos.

La observación participante y el diario de campo fueron dos elementos fundamentales, los cuales complementamos con entrevistas a profundidad. En esta etapa se contó con el apoyo del comité de padres de familia, cinco alumnos - tres homosexuales y dos heterosexuales- y cuatro profesores. Cabe destacar que el mayor interés por proyectar su voz se observó en los tres jóvenes homosexuales, quienes solicitaron plasmar sus palabras literalmente y de manera anónima. Es preciso mencionar que muchas de las charlas, observaciones y entrevistas que se sostuvieron con el alumnado y con los padres y madres de familia fueron en la lengua de la localidad, el tseltal, por lo que los extractos aquí presentados son el resultado de una transcripción y traducción posteriores.

Se buscó documentar las concepciones y los significados que los diferentes actores tenían acerca de la homosexualidad, además de que por medio de la observación participante fue posible presenciar manifestaciones tales como rechazos y agresiones - verbales y físicas - hacia los educandos en espacios de interacción. La libreta de notas fue indispensable para plasmar la información recopilada y que a partir de ella se establecieran las categorías, que ordenamos por ejes temáticos para la proyección de resultados.

\section{El antsiwinik: ser hombre-mujer en Damasco}

En las comunidades tseltales como Damasco no existe una expresión que se identifique con la palabra "homosexualidad"; antsiwinik es la aproximación más cercana, término que se refiere a una persona que puede hacerse pasar por hombre, y a la vez por mujer.

\begin{abstract}
Anteriormente eso no había, ahorita donde quiera que se vaya se ven los antsiwinik, se meten hombre con hombre, se visten como mujer. Eso no está bien, aquí en la comunidad hay poquitos, antes no había nada... pues los antsiwinik son eso, hombres que se visten o quieren ser mujer o que ocupan el lugar de una mujer cuando están con un hombre, no se ve bien porque los más chicos lo pueden aprender (padre de familia, entrevista realizada el 3 de febrero de 2017).
\end{abstract}

Desde la perspectiva del padre de familia entrevistado, ser antsiwinik, vestirse o asumir el rol sexual de una mujer siendo hombre, es algo que no debiera ocurrir porque representa un mal ejemplo para los menores, que pueden imitar o aprender de tales actos o modos. Entonces, se considera que ser antsiwinik es algo que se desarrolla y, por tanto, se trata de un proceso social que puede llegar a aprenderse en la interacción con otros que ya lo son. En este sentido, desde su acepción más básica-ontológica, el término homosexual fue acuñado a fines del siglo XIX por un psicólogo alemán, Karoly M. Benkert, quien menciona que se trata de la atracción hacia personas del mismo sexo. Aunque el término se enfoca en una orientación sexual no heteronormativa, las discusiones sobre la sexualidad en general son bastante amplias, sobre todo cuando se habla de comportamientos y expresiones "otras" —sexuales y de género-, pues según Preciado:

\footnotetext{
La homosexualidad no forma una categoría sexual bien definida, sino que recubre un conjunto de conductas variables, intercambiables; que no hay un tipo "homosexual", y que las "singularidades" que lo caracterizan pueden encontrarse en cualquier otro individuo que no se declara homosexual; en
} 
todo caso, que la separación "activo" y "pasivo" se ha vuelto obsoleta y ridícula, como la distribución entre hombre y mujer, como la atribución de la pasividad a lo femenino y de la actividad al carácter varonil (Preciado, 2009:8).

Ser homosexual o antsiwinik es sinónimo de opresión múltiple según los habitantes de la comunidad y en el mismo seno familiar, considerando que la organización y los roles sociales están enmarcados en la sexualidad heteronormativa y patriarcal, la cual determina que únicamente se puede ser "hombre" o "mujer" heterosexual, y a partir de ello la función que se debe asumir en la estructura social. Como afirma Michel Foucault: "el sexo no es un principio, sino un resultado de ciertas prácticas discursivas" (1978, citado en Chant y Craske, 2007:235-236). La cita anterior deja ver que el discurso y la práctica heteronormativa es lo que instituye el binario de género al establecer el "deber ser” de las prácticas sexo-genéricas. Sin embargo, ¿cómo podemos definirlas? Según Marcial:

[...] son prácticas culturales que movilizan saberes, creencias, valores y actitudes predominantes en determinado contexto social para el establecimiento de relaciones sexo-afectivas y sociales para el ejercicio de la sexualidad. Estas prácticas explican la vivencia y construcción de diversidad de identidades. Pues es simplista seguir pensando en una sociedad de normas heterosexistas que establece una dualidad genérica como única, correcta y no cambiante. De manera que, al legitimar sus diferentes prácticas dentro de una sexualidad transformadora, los sujetos también van reconfigurando y adaptando sus aspiraciones identitarias al tiempo-espacio y contexto en el que se desenvuelven, legitimando a su vez que estas prácticas son una forma de correlacionarse entre iguales y con los sujetos de su entorno, abriendo las posibilidades de visibilidad de una diversidad sexo/ genérica (Marcial, 2015:96).

Lo anterior da cuenta de comportamientos, discursos y prácticas, pero además de la reproducción o no de los roles sexuales y genéricos que existen en cualquier contexto contemporáneo, sea urbano o rural, pues el proceso globalizante nos atraviesa a todos como sujetos sin importar el tiempo o el espacio, como menciona Marcial. En este sentido, en Damasco se encuentran las siguientes concepciones:

Es que cada quien tiene que hacer, las mujeres tienen una función y los hombres también. Ellos, los hombremujer, se quedan en la casa, no salen, no trabajan casi, son como mujeres, pues. Aprenden lo que hacen las mujeres. El hijo de Mario siempre está con las señoras y pasa todo el tiempo en la cocina, nunca va a la milpa, hasta se pinta (padre de familia, entrevista realizada el 2 de marzo de 2016).

El Mateo es antsiwinik, no quiere ir al sector, dice que porque hay mucho calor, que lo va a quemar el sol [risas de compañeros] [...] Mentira, profe, si es el Diego antsiwinik, ese nunca va a la milpa, no puede trabajar (clase de agricultura, observación realizada el 7 de octubre de 2016)

Estos comentarios reafirman lo antes planteado, es decir, que el rol que se asume de acuerdo con el género es determinante, por lo tanto, ser antsiwinik también implica no asumir el papel o los trabajos que realiza un hombre dentro de la sociedad "indígena tseltal" de Damasco. Ello genera que, si una persona del sexo masculino es floja, no desea trabajar o realizar las actividades que representa ser winik (hombre), es objeto de burlas y de señalamientos peyorativos, y es llamado antsiwinik.

Por tanto, es importante mencionar que lo que sale de los parámetros heteropatriarcales y de la normativa heterosexual es como "lo abyecto"; aquello que cuestione el ideal hegemónico de la identidad heterosexual masculina es violentado de múltiples maneras, y es así como el ser considerado antsiwinik en esta comunidad implica que se tachen como incorrectos aquellos comportamientos afeminados y expresiones de género que pueden demostrar pasividad o debilidad - lo asociado a lo femenino - en sujetos biológicamente 
hombres. Desde la heteronormatividad, el ser varón implica ser un sujeto activo, proveedor y dominante, e incluso opresor de la diferencia, para demarcar el liderazgo que cobra sentido en varias sociedades contemporáneas. En ese aspecto, según narrativas de los miembros de la comunidad, la persona considerada antsiwinik es un mal ejemplo e induce a cambios riesgosos para la comunidad y para la sociedad, que normaliza la opresión no solo de identidades sexo-genéricas diversas, sino también de lo femenino y de cualquier expresión enmarcada dentro de la diferencia.

Pasa winikil es otra expresión común en las conversaciones entre padres y madres de familia y alumnos; significa "compórtate o actúa como un hombre", y comportarse como hombre implica asumir lo anteriormente planteado. El antsiwinik prácticamente no sale de su casa por varias razones; así lo expresa Omar:

Casi no salgo de la casa, profe, porque tantito voy a algún lugar, a la tienda o a donde sea que yo ande, rápido me quedan mirando, o los del campo me empiezan a chiflar o decir muchas cosas, siempre es lo mismo [...] Mi papá no me lleva a la milpa que porque es para hombres y no le gusta que me vean con él, porque según soy como mujer [...] pues sí me siento triste [yaj mel k’otan, siento triste mi corazón], pero no tengo a donde ir. En cuanto salga de la secundaria me iré a buscar trabajo a otro sitio porque aquí ya no quiero estar (Omar, entrevista realizada el 27 de enero de 2017).

En estas declaraciones puede apreciarse claramente que el rechazo social hacia quienes son sexo-genéricamente diversos en contextos indígenas es bastante similar al observado en zonas urbanas, e incluso podría afirmarse que es más agudo. Este rechazo, como consecuencia, genera en estos jóvenes "tristeza en su corazón" por la exclusión social de la que son objeto. Sin embargo, los jóvenes diversos no es que no puedan realizar los papeles asignados a los hombres — socialmente hablando-, el problema es que la misma norma social hace imposible que los lleven a cabo. En este sentido, la expresión pasa winikil solo es un argumento excluyente, pero que no determina que los antsiwinik no trabajen en la milpa o realicen otro tipo de labor en el campo: en general, el motivo de que no acudan a realizar estas labores, según lo observado, es la violencia física y verbal de la cual son objeto.

A pesar de lo anterior, en sus narrativas exponen comportamientos curiosos respecto a prácticas sexuales entre los jóvenes que se asumen como heterosexuales y los antsiwinik, pues estos últimos son en diversas ocasiones obligados a mantener relaciones sexuales o a realizar otras prácticas por el simple hecho de ser diferentes, lo que daña la integridad de los jóvenes sexo-genéricamente diversos y empodera a los chicos heterosexuales al establecerse relaciones de poder desiguales y violentas con los otros diferentes. Este hecho refleja factores que los planes de educación secundaria con enfoque intercultural no contemplan:

[...] me persiguen, que porque quieren estar conmigo, rápido me dicen "vamos al puente" o cosas como eso. Me jalan, me llevan... a la fuerza me quieren llevar aunque yo no quiera. Me muestran sus partes agarrándose con la mano, así lo hacen ellos, y según dicen que son bien hombrecitos, pero iquién sabe! (Ismael, entrevista realizada el 27 de abril de 2017).

En un juego constante de autonombrarse, los jóvenes heterosexuales realizan prácticas sexuales homoeróticas que no implican necesariamente que se asuman como antsiwinik. Tales prácticas sexuales se utilizan en el contexto mencionado como dispositivo de poder y de opresión para satisfacer necesidades propias y para oprimir a los diversos.

La homosexualidad como tal no existe y el concepto antsiwinik se atribuye únicamente a hombres; las mujeres no están incluidas en el concepto: "no, no, eso sólo se ve con los hombres, pues las mujeres son mujeres". En este sentido se expresaron en distintas ocasiones tanto alumnos como padres de familia, lo que invisibiliza aún más el tema de las identidades sexo-genéricas ${ }^{9}$ en estos contextos, donde se vive una discriminación social externa e interna - desde el mismo círculo social inmediato hasta el familiar-. 
La invisibilización de la mujer homosexual en la comunidad de Damasco, retomando la acepción de antsiwinik, puede deberse justamente a un posicionamiento heterosexista, es decir, a que se considera que la mujer ocupa un lugar fijo socioculturalmente hablando en términos de reproducción de roles sexuales y de género. Ello denota que se asume un comportamiento sociocultural normalizado que implica pasividad, sumisión y servicio al otro - al hombre proveedor-, cerrando la posibilidad a las mujeres de de-contruirse como sujetos, a la vez que se les niega la capacidad de agencia para transformar su realidad. Derivado de ello, se cierra la posibilidad a las mujeres de desarrollar conciencia para cuestionar el poder y la opresión a los cuales son sometidas, y se deja de lado esta mecánica de corrección de comportamiento y castigo para no excluirse de las líneas ideales del "ser mujer".

A esta serie de problemas hay que agregar la difícil situación que enfrentan al no contar con el apoyo de los padres ni de la sociedad en general porque no comprenden su orientación sexual; es decir, tienen que enfrentarse a un medio hostil en el cual se encuentra la propia escuela, además de otros espacios como las Iglesias. Es más, las ideas generalizadas que se les han impuesto desde distintos ángulos les han llevado a asumir una actitud homofóbica incluso hacia sí mismos.

A mí sí me gustan [los hombres], pero yo no lo digo, siempre me molestan, pero no lo digo, porque si lo saben no me van a dejar de molestar. Aparte mi papá siempre me pega, que porque parezco mujer, que le da mucha vergüenza tener un hijo antsiwinik. Me hace trabajar más, que para que me convierta en hombre. Dice que solo así me comportaré como hombre, que me va a buscar mi mujer cuando salga de la secundaria para que yo deje de pensar en otras cosas. Me obliga a ir al grupo juvenil... solo mis papas y el pastor lo saben. Pero no sé por qué soy así, no sé si sea malo. Ya en ocasiones me da asco cómo soy... pero mi papá no deja de pegarme desde que le dije que así soy. Él mismo me prohibió que dijera eso porque si alguien se entera me va correr de la casa (José Guadalupe, entrevista realizada el 7 mayo de 2018).

Ser antsiwinik es sinónimo de rechazo en el esquema social comunitario; esto implica que los jóvenes adolescentes oculten sus identidades diversas y orientaciones sexuales por temor al rechazo o a la violencia verbal y física que ello podría acarrear. Entonces, externar que se es antsiwinik implica ser objeto de señalamientos, burlas, persecución, rechazo, acoso y violencia constantes. Ante ello, reprimir los sentimientos es la alternativa que algunos jóvenes asumen para evitar la norma y los estándares socialmente establecidos.

La homosexualidad es algo que se sale de lo "correcto" o "normal"; estas perspectivas surgen de lo moral religioso ${ }^{10}$ pues, según esta perspectiva, es una distorsión de lo que naturalmente debe ser, pues una familia se integra a partir de un hombre y una mujer. Las acciones violentas dirigidas hacia los antsiwinik son para corregirlos o convertirlos en hombres heterosexuales; incluso la expulsión del núcleo familiar o comunitario es una muestra de opresión y exclusión que se vive en este contexto.

Según Segato, las acciones orientadas a la violación y el abuso o forzamiento sexual son moralizadoras y correctivas: "el violador es el sujeto más moral de todos. En el acto de violación él está moralizando a su víctima" (citada en Sietecase, 2017:s/p). A su vez son actos de imposición de dominio y poder sobre el otro. Los varones en su mayoría actúan bajo el mandato de la masculinidad, que es, como afirma Segato, un mandato de potencia, y la forma en que esta potencia se demuestra es dominando los cuerpos de las mujeres. Si bien la autora se refiere en este caso a la violación y al ejercicio de poder sobre el cuerpo de las mujeres, es importante distinguir que los jóvenes que sufren violencia sexual por parte de sus compañeros son simbólicamente feminizados, y es por ello que la violencia sexual ejercida hacia ellos juega un papel moralizante y castigador que empodera a los varones heterosexuales, legitimando la heteronormatividad. 
El antsiwinik y la interculturalidad en el contexto escolar: tarea pendiente al interior de la escuela y de los programas de estudio

La interculturalidad en un contexto de diversidad ha sido visualizada como un proceso institucional, considerando básicamente las relaciones humanas, y reivindicativo, que toma en cuenta la diferencia como un valor para el aprendizaje equitativo. La interculturalidad es un tema demasiado amplio para ser abordado en una sola investigación, por lo que en este trabajo no se pretende dar una definición del concepto, sino abrir otros posibles significados. El concepto presenta facetas en las que cada persona que investiga ha de profundizar de acuerdo con sus intereses sociales, económicos, políticos, educativos, sexuales, etcétera. Para efectos de este artículo, problematizamos en torno a la interculturalidad con un enfoque en la falta de amplitud y atención hacia la diversidad sexogenérica que se produce al interior de la escuela y en los programas de estudio.

En los ciclos académicos durante los cuales se llevó a cabo la investigación, el sistema de educación secundaria se encontraba regido por el plan de estudios de educación básica 201l; tanto ese como el actual modelo educativo de 2018, en sus contenidos no mencionan la diversidad u orientación sexual en la escuela como un tema que forme parte de la interculturalidad; este concepto se vincula únicamente con las relaciones culturales con los grupos "indígenas", tal como se plantea al principio del presente artículo. La perspectiva de Guillermo Núñez es sumamente interesante, pues dista mucho de aquellos discursos que reproducen estereotipos sobre las personas indígenas al considerarlas como: "seres oscuros, atávicos, anclados en el pasado milenario, encerrados en sí mismos, apacibles, casi inmóviles y desmotivados", o, como cuestiona el mismo autor, "seres primigenios, más cercanos que el resto de la población a una condición humana 'natural', la cual se corresponde al orden moral". ¿No es acaso esta mirada otra forma velada de racismo? ¿De paternalismo y desprecio que son alentados por actores sociales gubernamentales o por otros agentes sociales que se asumen solidarios con las causas indígenas, al considerarse que la sexualidad "natural" y legitimada es la heterosexual y cualquier expresión disidente como la homosexualidad es calificada como resultado de la influencia nociva del exterior? (citado en López, 2013:196-197).

Del mismo modo, en la práctica docente y en los cursos de actualización no se ha dado la importancia necesaria a este tema; incluso se observa como un asunto que no afecta en el proceso enseñanza-aprendizaje $y$, al no estar incluido en los programas de estudio, los profesores afirman que no tienen la obligación de abordarlo en el aula:

Realmente no hemos trabajado sobre la homosexualidad en la escuela ni en los cursos. En los programas de estudio no está, me imagino porque no tiene que ver con el proceso enseñanza-aprendizaje [...] tampoco los padres de familia nos permitirían hablar acerca de ese tema. Nosotros seguimos el programa de estudio, pero estos chavos igual también en la escuela nomás no dan una, son bien flojos (docente de la escuela, entrevista realizada el 9 de mayo de 2018).

El profesor señala y reconoce que, efectivamente, no existen temas específicos desde los cuales se trate la homosexualidad en los programas de estudio. Aunque habría que aclarar que ser antsiwinik no es sinónimo de ser homosexual, sino que el concepto conlleva otras cargas culturales como los límites de la sexualidad y las formas de ser y construirse sexo-genéricamente, pues la identidad no es estática, es cambiante, además de incluir otras acepciones que ya se señalaron anteriormente. Por ello, cabe mencionar una perspectiva contemporánea acerca de las identidades sexuales y de las expresiones de género diversas como la teoría queer. En este sentido, quizás el cambio social reciente más significativo concerniente a la homosexualidad sea la emergencia del movimiento de liberación gay en Occidente. En los círculos filosóficos este movimiento está representado, en parte, por un grupo bastante heterogéneo de pensadores que se agrupan en torno a la "teoría queer". ${ }^{2}$ 
Un tema central de los que propone dicha teoría es la determinación de si la homosexualidad - y por lo tanto también la heterosexualidad y la bisexualidad- es construida socialmente o si está impulsada puramente por fuerzas biológicas.

En el testimonio anterior, es necesario recalcar el señalamiento que el docente hace sobre estos alumnos - a los que considera flojos, que nomás no dan unasin prever o considerar la situación emocional que estos experimentan dentro y fuera de la escuela. En el nuevo modelo educativo 2018 se menciona la inclusión de grupos que por cultura, historia u orientación sexual han sido excluidos, pero se sigue considerando la interculturalidad sobre la base de relaciones e intercambios culturales, señalando una vez más a los grupos "indígenas" como los que deben ser protagonistas de esta interculturalidad.

No se han desarrollado hasta el momento, al menos desde los programas de estudio, estrategias que contribuyan a una educación intercultural que considere la diversidad sexo-genérica al interior de la escuela pese a las vivencias que gran parte del alumnado experimenta. Así se puede observar en la siguiente cita:

Es que me toquetean mucho. Cuando vamos al sector de agricultura siempre me dicen chula, kijnam (mi mujer), me chiflan. Peor en el arroyo, ahí sí me han agarrado, más el Jerry y el Abednego. Dicen que son muy hombres, pero bien que les gusta estarme agarrando [...] No, el profe de agricultura no dice nada, en ocasiones también sí me defiende, pero les dice a los otros: "no molesten a la nena", y todos se empiezan a reír (Ismael, entrevista realizada el 14 de noviembre de 2017).

Como se ha mencionado, los jóvenes de la EST 62 que se asumen como antsiwinik son objeto de discriminación al interior de la escuela y, más que eso, de violencia física y psicológica sin que los docentes tomen medidas para actuar ante las relaciones asimétricas con sus compañeros; incluso favorecen que el ambiente sea más perjudicial para estos. Una de las consecuencias de lo anterior se muestra en el siguiente testimonio:
Yo no quiero seguir estudiando, me molestan aquí en la escuela, mi papá me regaña, me pega, nadie me quiere. Todos se burlan de mí, ni ganas me dan de venir a clases, pero igual vengo porque ni allá me quieren ver también que porque soy antsiwinik. Pero me voy a ir de aquí de verdad, yo me voy a ir, aquí la gente es muy, no sé, y los maestros de verdad nada hacen. ¿Qué vas a querer aprender?, ino dan ganas! (Omar, entrevista realizada el 14 de febrero de 2017).

La situación de los antsiwinik al interior de la EST 62 es complicada. Algunos de ellos presentan problemas de reprobación y falta de interés por las actividades escolares, como señaló un docente cuyo testimonio se mencionó líneas arriba, tema que se refuerza en las palabras de uno de los alumnos. Pero hay una gran diferencia entre los testimonios de uno y de otro, el educador los señala como flojos, y el educando atribuye su falta de interés al acoso constante del cual es objeto, que lo aísla de manera consciente. Es lógico que ante el acoso y la violencia que se vive dentro de la escuela el alumno tenga poco interés en su formación académica. No hay ejemplos que emular en un sistema en el que los maestros y los programas de estudio no hacen lo suficiente para atender a estos grupos.

\section{Reflexiones finales}

El recorrido del presente artículo ha servido para ofrecer un acercamiento a la situación que viven jóvenes adolescentes considerados antsiwinik de la escuela secundaria técnica 62 de la comunidad de Damasco, municipio de Ocosingo, Chiapas. En este proceso se pueden observar las limitaciones que la comunidad y la escuela presentan con respecto a las personas con identidades sexo-genéricas diversas.

Ser antsiwinik no es sinónimo de homosexualidad, porque el homosexual como tal en el contexto tseltal de Damasco no existe. En cuanto a las mujeres, no se considera que puedan tener una orientación sexual distinta a lo establecido por el orden social, en el que ellas deben tener un marido. El antsiwinik es un hombre al que se le han atribuido comportamientos 
socioculturalmente asignados a mujeres, es por ello que son sujetos rechazados y violentados en el contexto en el que se desenvuelven.

La escuela está lejos de ser un espacio intercultural o de buscar el diálogo entre personas diversas. En los programas oficiales de las reformas educativas de 2011 y 2018 no existen estrategias que contribuyan a generar espacios de convivencia, inclusión, respeto y aceptación; sí entre grupos culturalmente diferentes, pero no se menciona a jóvenes con identidades sexogenéricas y orientaciones sexuales diferentes a lo establecido como moral y socialmente "correcto" en Damasco.

La interculturalidad aún sigue apostando por las relaciones culturales desde distintos ángulos, especialmente con los grupos denominados indígenas, pero se deja de lado a jóvenes como los antsiwinik, que son objeto de maltrato y marginación Sin embargo, por la carga despectiva y negativa que sufren, es imperativo considerar la falta de atención, respeto e inclusión que experimentan día a día las personas cuya identidad diversa u orientación sexual no se encuentra dentro del marco que la sociedad heteronormada ha establecido como lo "correcto" e inamovible.

Es necesario que la interculturalidad no se remita a relaciones culturales y a la reivindicación de grupos excluidos como los pueblos indígenas, sino que debe ampliarse el horizonte e incluir a los sujetos sexogenéricamente diversos en este proceso. La escuela es y seguirá siendo un baluarte central para lograr transformar los esquemas socioculturales que laceran a otros, no sin antes modificar los programas de estudios para que atiendan puntualmente situaciones discriminatorias de este tipo.

Los antsiwinik son jóvenes que, como cualquiera, tratan de ser respetados en una sociedad que los excluye. Son jóvenes cuya voz ha sido ignorada, pero que debe empezar a escucharse para crear una escuela, una sociedad, una realidad y un mundo en los que una educación transformadora intercultural sea posible.

\section{Notas}

${ }^{1}$ Son categorías coloniales que no representan una significación específica.

2 Según la Academia Mexicana de la Lengua, hasta hace unos añoslasformas preferenteseran "tzeltal" $y$ "tzotzil". En la actualidad, "tseltal" y "tsotsil" se consideran formas únicas para nombrar estas lenguas, ya que así se produce una mayor uniformidad ortográfica.

${ }^{3}$ Otra definición del sistema sexo-género es: el sistema de relaciones sociales que transforma la sexualidad biológica en productos de actividad humana y en el que se encuentran las resultantes necesidades sexuales históricamente específicas.

${ }^{4}$ La comunidad de Damasco cuenta con doce iglesias, en su totalidad protestantes.

${ }^{5}$ Para efectos de la investigación se manejan nombres ficticios a fin de proteger la identidad de quienes apoyaron la investigación.

${ }^{6}$ Heteronormatividad es un concepto de Michael Warner.

7 En Chiapas, la cultura pública relacionada con la homosexualidad masculina no escapa a ello. Anzilwinik - mujer hombre - se nombra al hombre homosexual en tsotsil, nalanixuk nalanwinik - mitad mujer, mitad hombre- en tojolabal, banchues en zoque, o bien, despectivamente, mampos en el sureste mexicano y en parte de Centroamérica. Se pueden agregar otras dos miradas que, situadas en polos extremos, pueden derivar o bien en la celebración colectiva de la transgresión de los roles sexuales que han sido impuestos social e históricamente, o en el desprecio expresado con el uso de la violencia extrema contra cualquier expresión de disidencia sexual masculina.

${ }^{8}$ Muchas de las palabras son mencionadas en la lengua de la comunidad, otras que no tienen traducción se traducen con el carácter peyorativo que caracteriza al original.

${ }^{9}$ Entendida a grandes rasgos como la vivencia psicológica (subjetiva) de poseer un sexo y sentirse perteneciente a uno de los géneros sexo-sociales, en ocasiones independientemente de la biología del sujeto. 
${ }^{10}$ Hay que considerar que la comunidad de Damasco es en su mayoría protestante y los valores morales marcados por la religión están a flor de piel; las iglesias y el pastor juegan un papel importante en lo que se considera correcto en la comunidad.

"1 Se pone el concepto entre comillas dado que lo consideramos un término colonial porque los grupos culturales no fueron parte del proceso de significación $\mathrm{u}$ asignación de dicho concepto. Es preciso aclarar que nos encontramos realizando una investigación en proceso al respecto.

${ }^{12}$ Término que, según Pickett (2002), no tiene equivalente en español. Se pronuncia "cuíer" y en inglés significa "extraño" o "raro", pero por décadas se usó como insulto con el significado de "homosexual". En otros textos puede traducirse por "puto", pero aquí ha sido "resignificado", si es que esto es posible, para designar una escuela de pensamiento.

\section{Referencias}

Aguilar García, María Teresa (2008). "El sistema sexogénero en los movimientos feministas". En Amnis, 8. Disponible en: https://journals.openedition.org/ amnis/537 (consultado el 4 de abril de 2019).

Bourdieu, Pierre (2000). La dominación masculina. Madrid: Anagrama.

Chant, Sylvia y Nikki Craske (2007). Género en Latinoamérica. México: CIESAS.

Hernández Silvano, Amadeo (2012). "Discriminación y racismo en la práctica educativa de una escuela intercultural: El caso de la Escuela Secundaria Técnica. № 62 de Damasco, Ocosingo, Chiapas". Tesis de Maestría, Universidad Politécnica Nacional, México.

López Moya, Martín de la Cruz (2013). "Guillermo Núñez Noriega (2009), Vidas vulnerables. Hombres indígenas, diversidad sexual y VIH-Sida". En LiminaR. Estudios Sociales y Humanísticos, 1l(2), 195-197. Disponible en: http:// liminar.cesmeca.mx/index.php/rl/article/view/231 (consultado el 8 de mayo de 2019).

Marcial Zavala, R.E. (2015). "Identidades muxes' en Juchitán, Oaxaca: prácticas sexo/genéricas y consumos culturales". Tesis de Maestría. Universidad Autónoma de Chiapas. Tuxtla Gutiérrez.

Pickett, Brent L. (2002). "La homosexualidad, vista desdela filosofía. SIGLA (Sociedad de Integración Gay, Lesbica Argentina)"[Blogdeinternet]. Buenos Aires.Disponible en: http://www.sigla.org.ar/index.php?view=article\&e atid=44:espejo22\&id=105:la-homosexualidad-vistadesde-la-filosofia\&eoption=com_content (consultado el 10 de mayo de 2019).

Ponce, Patricia (2004). "Masculinidades diversas". En Desacatos, 16, 7-9. Disponible en: http://www.redalyc. org/articulo.oa?id=13901601 (consultado el 10 de agosto de 2018).

Preciado, Beatriz (2009). El deseo homosexual. Barcelona: Melusina.

Salazar Barrón, Sergio (2016). "La ciudad y el género: la producción urbana del espacio heterosexual". En Bitácora Arquitectura, 33, 98-103. Disponible en: http://www.revistas.unam.mx/index.php/bitacora/ article/view/57357/50898 (consultado el 8 de enero de 2019)

SEP (Secretaría de Educación Pública) (2011). Plan de estudios 201l. Educación básica. México: SEP.

Sietecase, R. (2017) "Rita Segato: La violación es un acto de poder y de dominación”. En La Vanguardia, 14 de abril. Argentina. Disponible en: http://www. lavanguardiadigital.com.ar/index.php/2017/04/14/ rita-segato-la-violacion-es-un-acto-de-poder-y-dedominacion/ (consultado el 12 de julio de 2018).

Stang, Fernanda (2018). La invisibilidad estadística de la diversidad sexual y de género en los censos latinoamericanos. "Aspectos conceptuales de los censos de población y vivienda: desafíos para la definición de contenidos incluyentes en la ronda 2020". Santiago de Chile: CEPAL. Disponibleen: https:// www.cepal.org/sites/default/files/presentations/01 fernanda_stang_celade.pdf (Consultado el 5 de mayo de 2019).

Vilche, Laura (2017). "La primera víctima del mandato de masculinidad es el hombre". En Diario La Capital, 22 de agosto. Argentina. Disponible en: https:// www.lacapital.com.ar/ovacion/la-primera-victimadel-mandato-masculinidad-es-el-hombre-nl456007. html (consultado el 4 de mayo de 2019). 
Wences-Acevedo, Rosalio (2016). "Heteronormatividad y matrimonio entre personas del mismo sexo". En María del Rosario Figueroa Varela y Laura Isabel Cayeros López (eds.), Ciencias Estudios de Género. Handbook T-II. Tepic, Nayarit: ECORFAN, pp. 194-
203. Disponible en: http://ecorfan.org/handbooks/ Ciencias\%20Estudios\%20de\%20Genero\%20TII/22. pdf (consultado el 3 de mayo de 2019).

Wittig, Monique (2006). El pensamiento heterosexual y otros ensayos. Barcelona: Egales. 